\title{
Neither Carnival nor Lent: Everyday Working Class Drinking
}

The true role of drinking in Edwardian Britain was much more humdrum. Beer was the basis of leisure. It took the place which later became filled with cigarettes and television. Children would fetch jugs from the pubs for tired parents to relax at home at the end of the day. At funerals, at weddings, at harvest, at the initiation of apprentices, at ordinary work breaks, a glass of beer would be exchanged. ${ }^{1}$

For most of the nineteenth and early twentieth centuries, moral and political concerns about alcohol consumption rested on the types of working-class drinking behaviour constantly on show in pubs and on the streets. Yet as the quote above suggests, there was another side to working-class drinking where alcohol formed an ordinary part of everyday life. The quote is from Paul Thompson, a sociologist who conducted an oral history study of Edwardian family life. ${ }^{2}$ By stepping into the private world of the family, Thompson's study revealed a culture of 'everyday' drinking among ordinary people. Accounts of excessive drinking were widely documented in the press and in official reports, yet the more humdrum, routine and private drinking habits that existed across the social spectrum largely escaped public scrutiny.

The chapter draws upon an analysis of oral history transcripts which offer glimpses of the ways in which working-class men and women consumed alcohol and their reasons for doing so. This is not a 'top down' vision of working-class drinking skewed by political motives or temperance ideology. Instead, it offers first-hand accounts of drinking https://doi.org/10.1007/978-3-319-92964-4_11 
based upon the experiences and memories of surviving Victorians and Edwardians. Many contemporaries (and some historians) looked no further than the publicly drunken aspects of Victorian working-class drinking culture that seemed to be evident on city streets or in pubs, theatres and dance halls. Joseph Gusfield argues that this type of 'carnival and lent' analysis of working-class drinking can be traced to the process of industrialisation and the consequent separation between daily work and leisure. ${ }^{3}$ As alcohol consumption was less acceptable in the workplace, it became a marker of leisure time-a symbol of free time spent away from work. The drinking culture of the working classes was viewed as 'carnivalesque' precisely because it ran counter to the sobriety, efficiency and self-control demanded by industrial capitalism. Yet for many working-class families, free time was spent at home, where alcohol formed an integral part of the daily routine that signalled the end of the working day.

Leisure time was one of the many aspects explored in Thompson's study of Edwardian work and family life. The research was conducted in the 1970s when it was still possible to interview surviving Victorians and Edwardians in Britain. The study comprised 444 interviews with men and women all born between 1872 and $1906 .{ }^{4}$ Thompson endeavoured to provide a representative sample of the Edwardian population based upon the 1911 census. The interviewees consisted of men and women from all social classes and occupational groups who were living in urban and rural regions of England, Scotland and Wales. The interview schedule consisted of a list of questions that included the roles and work of family members, for example cooking, dining, domestic routines and family values. The interviews were open-ended and some of the questions concerned alcohol consumption. The main questions relating to alcohol were

1. Did your mother or father brew their own beer or make wine? (this question was only directed at working-class interviewees).

2. Did your mother or father go to the pub? (this question was put to all the interviewees).

The interviews lasted between one and six hours and therefore the original transcripts are lengthy (a full extract of data from the original transcripts can be found in the Appendix). ${ }^{5}$ The questions on alcohol were mostly asked in a set order but a close reading of the interview 
transcripts revealed that the interviewees sometimes provided additional anecdotal information about alcohol in other sections of the interviews. Both working-class and middle-class people were interviewed and asked questions that related to alcohol consumption and drinking behaviour. The middle-class interviews will be dealt with in the next chapter which considers the private drinking culture of the higher classes.

The Edwardians study is relevant because it goes beyond the 'carnivalesque' drinking culture of the streets to examine drinking in the context of everyday family life where alcohol formed a part of the daily routine. This offers insights into how working-class people thought about drinking and also into the ways in which alcohol was produced and consumed. There is rich qualitative data on attitudes towards alcohol consumption, which sometimes reflect the social and cultural values of different groups of working-class people. Yet the use of oral history transcripts can have potential pitfalls: These were old men and women recollecting events from their childhoods and they may have forgotten or exaggerated details. However, this was a large representative study that interviewed a wide range of people and it is possible to see patterns in the responses, which suggests some accuracy of detail. But accuracy was not the main reason for using the oral history transcripts. The study provides a unique opportunity to 'listen' to what Victorians and Edwardians had to say about alcohol consumption and to set their discussions and views within the social and cultural context of the time. It was not intended to use The Edwardians study to uncover any 'truths' about alcohol consumption but instead to gain deeper insights into different types of drinking.

Another relevant sociological study is The Pub and the People, which was a Mass Observation Study conducted in 'Worktown' in the 1930s. ${ }^{6}$ Worktown was in fact Bolton, an industrial town in the north of England which had a population of 180,000 people and 300 pubs. The study was conducted over four years between 1938 and 1942 and involved qualitative interviews, observation and the collection of data and statistics. Although the study offers a snapshot of drinking behaviour in the interwar years, some of the interviewees had been alive in the Victorian and Edwardian periods and therefore they brought with them some ingrained drinking habits and attitudes towards alcohol consumption. The interviewees shared their reasons for drinking particular types of alcohol and these reasons offer insights into the ways in which working-class consumers justified their drinking behaviour. 
The Worktown study provides a contrast to The Edwardians study because it focuses on the public drinking culture of the pub whereas The Edwardians drinking is largely situated in the home. When combined, these studies provide insights into working-class drinking within different social, spatial and temporal contexts.

For Victorian and Edwardian working-class families, patterns of drinking largely revolved around family life and home consumption of alcohol was as popular as visiting local pubs. Some of the interviewees recalled the daily trip to the local pub to buy dinner beer

I remember some of the older boys going round to fetch the supper beer which was a pint of beer for tuppence, you see they [parents] had a glass each out of that for their supper. But none of us were ever allowed to taste it. But the older boys were allowed to go round with the jug in those days - there wasn't bottled stuff and things you see. And it was considered dreadful for a younger person to be in a pub you see - so that it was only the older ones who were allowed to fetch the supper beer - or perhaps my mother or father would fetch it themselves you know."

Drinking beer with the evening meal seems to have been a common feature of working-class life for both men and women but it was mainly men who went to the pub regularly in the evenings. One interviewee, a man from Essex, was asked if his mother and father drank beer with their evening meal. He only recalled his mother having a half pint of porter every evening with supper and instead his father would visit the local pub in the evenings. When asked if his mother and father ever went to the pub together, he replied that in his town women did not enter pubs and instead were more likely to consume alcohol at home. ${ }^{8}$

In a study of pubs in York in 1900, Seebohm Rowntree observed the gender differences of customers who frequented different pubs in the town. ${ }^{9}$ He noted marked variations in the numbers of men and women who went to different pubs located in working-class districts. In the slums and in poorer working-class areas, women drinkers were a more visible presence within pubs. Yet in more affluent working-class areas, women still visited pubs but many went only to fetch the dinner beer. Rowntree noted that these women were 'all respectably dressed and of cleanly appearance' and that within the pubs under observation 'no cases of extreme drunkenness occurred'. ${ }^{10}$ Rowntree drew a distinction 
in terms of respectability between women who drank in pubs and those who drank at home. In those terms, it was not the act of drinking alcohol that challenged feminine norms but rather the location of alcohol consumption. This mattered less for men's drinking behaviour which was governed by different social rules. Working class fathers' drinking revolved around family life and daily routines. Drinking beer with dinner seems to have been common, as was visiting local pubs in the evenings. Interviewees from urban and rural regions of Britain recalled their fathers' regularly going to local pubs and working men's clubs to socialise and to conduct business

Interviewee $(J F)$ : He'd [father] go out and have a drink because at those times-they used to do a lot of business in the pubs, you see, he'd meet different people in these pubs and they'd say, all right Bill, will you make me a suit you see and he'd meet them in these places ... And they'd come into this boozer and just pay him a shilling or two shillings-whatever they could afford [for the suit].

Interviewer: Did he stick to the same boozer?

$J F:$ Oh no he went to several and then some evenings he went to whist drives and they were held at these public houses you know. And he's probably go there perhaps one night or two nights a week. ${ }^{11}$

The Pubs and the People study focused on the pub as a social institution. The study listed the types of activities that people (mostly men) did in pubs. These included: drinking; smoking; playing cards; dominoes; darts and quoits; singing and listening to the piano; betting and talking about-sport, work, people, drinking, the weather, politics and 'dirt' (scandal). The pub was also a venue for a range of other activities such as weddings and funerals, trades union meetings, secret societies, finding work, crime and prostitution, sex and gambling. ${ }^{12}$ The study found that for most people in Bolton, 'drink' meant beer (usually the local beer known as 'mild') and that most drinkers' preferences were motivated by price rather than quality, taste or fashion but again there were gender differences in consumption

Men are guided by price [of beer] first. Women, who often have men pay for them, go more for taste and the externals. It is more 'respectable' for women to drink bottled beer, mostly bottled stout or Guinness, seldom mild. ${ }^{13}$ 
In order to find out the reasons why people mainly drank beer, the researchers ran a questionnaire competition that offered financial incentives for consumer participation. The top reasons given for drinking beer were 'social reasons' followed by 'health'. The health reasons were broken down into sub-categories

- General health-giving properties-24\%

- Beneficial effects connected to work-17\%

- Good effect on appetite-14\%

- Laxative effect-10\%

- Nourishing-6\%

- Tonic-8\%

- Valuable properties in malt and hops-6\%

- Vitamins-6\%

- Diuretic-2\%

The researchers believed that many of the health reasons given by respondents were a direct result of brewers' advertising and marketing tactics

Many people use the phrase 'beer is best'. This is a clue to the large number of references to its health-giving properties; phrases like 'it is body building' - 'picks a man up' - are a direct reflection of brewers' advertising. In the days before mass beer propaganda people drank considerably more than they do now. The history of the last hundred years of drinking in England is a history of decline. These [questionnaire responses] definitely show how advertising phrases intended to keep up consumption have become a part of pub-goers mental attitude to their beer. Beer more than anything else has to overcome guilt feelings. That is why advertising is simple, insistent, fond of superlatives, visual and often showing other people drinking the stuff, radiant with good cheer or good looks. ${ }^{14}$

The researchers concluded that consumers were caught in a trap between temperance and brewers' propaganda, which sought to convince people that drinking was either harmful and sinful or healthy and good. Since the pub was such a central aspect of social life, people either consciously or subconsciously chose to believe the brewers hype. The notion that 'beer is best' had become a deeply ingrained and almost unconscious justification for consuming alcohol. Some of the respondents offered their 
personal reasons for drinking beer. One man aged 66 gave his reasons for drinking beer

... because it is a food, drink and medicine to me. My bowels work regular as clockwork and I think that is the key to health. Also lightening affects me a lot, I get such a thirst from lightening and full of pins and needles, if I drink water from a tap its worse. ${ }^{15}$

Aside from health reasons, the study also considered why men in particular drank beer and found that many of these reasons related to concepts of masculinity and heterosexuality. Some men stated that beer 'put lead in their pencil' or alluded to their drinking habits having a positive effect on their sex lives and even improving their marriages. When asked why he went to the pub and drank beer, one man aged 25, described as a 'shop assistant type' replied 'What else can a chap do in a one-eyed hole like this, he'd go off his chump if there were no ale, pictures and tarts.' 16 This explanation perhaps comes closest to situating beer as an escape or a distraction from the monotony of men's daily lives. The idea that beer consumption somehow boosted masculinity and aided sexual function is not something that could be directly attributed to the effects of brewers' marketing tactics. It could have arisen from the masculine environment of the pub and from the ways in which beer was consumed. Most working-class men drank the local draught beer ('mild' or 'best') in either pints or gills (quarter of a pint) and this distinguished them from women who drank stout, Guinness or bottled beers. It also made 'mild' a 'man's drink' that was therefore imbued with masculine qualities. Add to this the largely male environment of the pub-particularly during weeknight evenings when men would 'escape' the home for a couple of pints—and it is hardly surprising that the consumption of beer became associated with an idealised view of male heterosexuality. Many of the male drinkers in the Worktown study were undoubtedly husbands who 'went home to the wife' at night and therefore it still fell within the scope of 'respectable' drinking if beer consumption was viewed as enhancing rather than diminishing their conjugal roles.

The masculine aspect of beer drinking is also evident in The Edwardians study. Most interviewees stated that their fathers drank moderately-one or two pints at most, and few recalled their fathers being drunk. Some also stated that their father would only visit local pubs at the weekends or in the evenings when finances permitted and instead 
much of their father's drinking was confined to the home. In a study of late Victorian working-class life, Meacham argues that working-class men were divided between teetotallers who stayed at home in the evenings and beer drinkers that went to the pub for a pint or two in the evening. ${ }^{17}$ Meacham also believes that working-class men preferred to spend their leisure time in the company of other men and highlights the importance of working men's clubs, which grew in popularity in the late nineteenth century as places where working men could meet, socialise and drink

There can be little doubt that a working man of moderation, who spent his leisure hours in a well-managed and generally reputable club, was contributing not only to his personal enjoyment but to his neighbourhood image as a respectable and responsible member of the community. ${ }^{18}$

Although this acknowledges the importance of sociable drinking within working men's clubs and pubs in terms of cultivating and reinforcing ideas about masculinity the analysis misses the significance of domestic drinking where men and women drank together. Some of The Edwardians interviewees recalled their parents drinking at home, particularly in regions where it was considered socially unacceptable for women to drink in pubs

Interviewer (I): What about your mother, did she like a drink?

Interviewee $(A)$ : No.

I: She never went with him [father] to the pub?

$A$ : Oh, good gracious me, not in those days!

I: Respectable women didn't?

A: No.

I: Do you think that none of your mother's friends ever went, either, the people she knew, they wouldn't have gone along?

$A$ : I think that the people my mother associated with would not have gone to a public house.

I: If they wanted a drink anywhere, how do you think they got one?

$A$ : We wouldn't have gone, but Father might have gone down to what is commonly known as The Rats Hole-it was known as The Rats Hole always has been-and he would have taken a jug down and brought a jug of beer back home.

I: And they'd have a drink together?

A: Yes. ${ }^{19}$ 
In some regions women were not as constrained by gender norms. One of the interviewees recalled how her mother and other local women met every Monday and had a drink together. The interviewee was born in 1898 and grew up as part of a large working-class family in London

Well on the Monday - she had a few coppers so her and a lot of women used to go out - mother's day they used to call Monday. And they'd dance down in the ground in the building, you know. They'd enjoy themselves. My mother used to play a mouth organ. And we always knew - Monday, oh my mother'd always have a sweet for me when I came home from school but we always knew when Monday came what to expect. No arguments - people'd be happy, all the neighbours, you know, but my mother didn't mix up with them a lot but it was Monday [and] they seemed to go out and have a drink together. They'd put all their coppers together and they'd have this drink between them and - they never used to get drunk, never had that money. But they'd have perhaps one or two drinks, come back and start dancing. Enjoying themselves. ${ }^{20}$

'Mother's day' was a weekly gathering of local women, which involved a trip to the pub followed by music and dancing in the streets. Few of the other interviewees talked of their mothers drinking publicly in this way. Yet this woman made it clear that in her community, it was customary for the local women to get together once a week and have a drink. Perhaps in some working-class areas of London this type of celebratory drinking was considered normal for women. Yet the majority of interviews described working-class women either drinking at home or to going to the pub in the company of husbands or other male family members

Interviewer (I): You told me your mum and dad used to go out for a drink?

Interviewee (LB): Oh yes. Yes. That was their treat-yes.

$I:$ In those days were women allowed to go in pubs?

$L B$ : Oh yes. Yes. Yes. The first place-there was-it's a little place-I don't know whether it's still there-It was called The Money up Hodge Lane and - they used to have a sing-song of a Saturday night.

$I:$ There was no prejudice against women going?

$L B$ : Oh no-none at all. And-they used to have a sing-song of a Saturday night. ${ }^{21}$ 
In some working-class communities, it was considered socially acceptable for women and children to go to local pubs to obtain alcohol for home consumption. One interviewee born in Dorset in 1904 remembered her grandmother's drinking habits and how she used to regularly visit the local pub to get beer to take home and drink with friends

\begin{abstract}
Now my grandma - I tell you - when I was - how old was I - about twelve or thirteen I suppose - oh she must have been - must have been going on a long time before that, but I can particularly remember - you know they used to wear the capes, the old ladies, and a little bonnet with a - rose in the - or something in the front, and tied under the chin? Well she used to put her cloak on, take her little jug, go down to what used to be The Prince of Wales. Go down there and get a - half pint of stout. Go home, take her bit of cheese, and she used to go down to a friend's called Mrs Tizzard - Emma we called her. And she used to take her bread and cheese and her half pint of stout down there and have that there with Emma. I can see her now. With her cloak and her little jug, you know. ${ }^{22}$
\end{abstract}

Stout was a popular drink among women, particularly during pregnancy and after childbirth. This popularity could have stemmed from advertising which promoted the health-giving and nutritious properties of beers and stout (see Figs. 11.1 and 11.2).

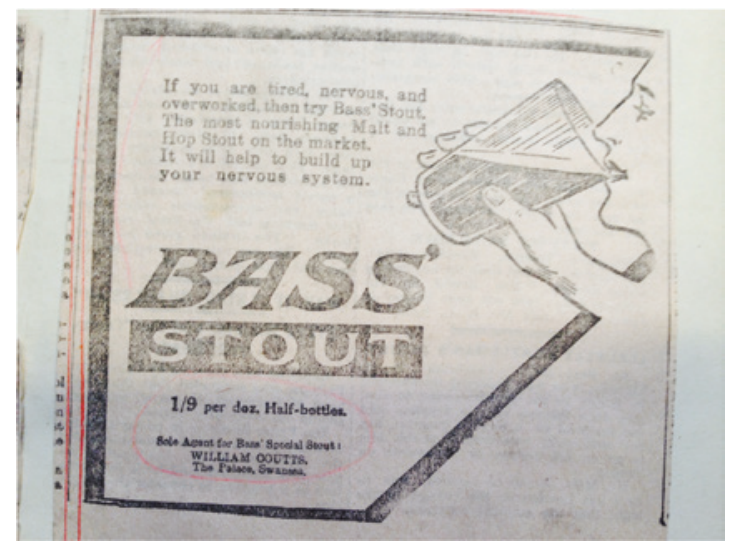

Fig. 11.1 Bass \& Co. advertisement c. 1900-1910, Courtesy of The National Brewery Centre ${ }^{23}$ 


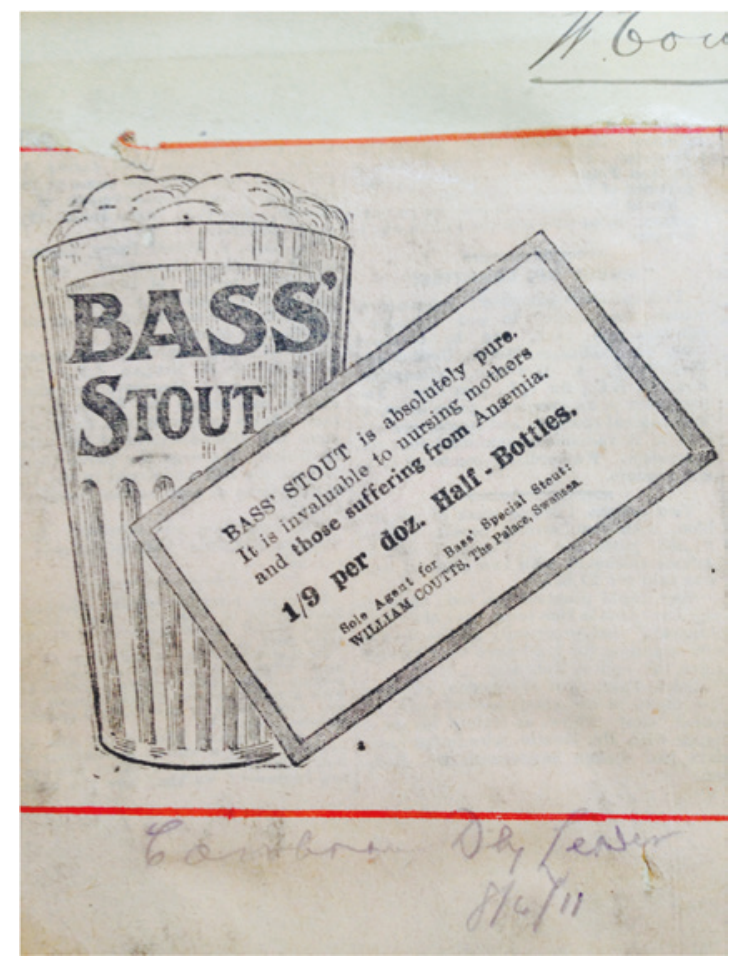

Fig. 11.2 Bass \& Co. advertisement c. 1900-1910, Courtesy of The National Brewery Centre ${ }^{24}$

One interviewee who was born in Essex in 1881 recalled his mother drinking stout during pregnancy, even though his father was a teetotaller. ${ }^{25}$ Another interviewee who grew up in London had similar memories of her mother drinking small quantities of stout on a regular basis

I remember mother used to have a bottle - a quart bottle of stout - very reasonable in those days - used to last her a week. She used to have a little drop in a glass like that - and then of course we'd all say to her can we have a little drop. ${ }^{26}$

Bottles of stout and jugs of beer from pubs were not the only ways that working-class women obtained alcohol. It also seemed to be common to brew beer and herbal wines for home consumption. Most of the working-class interviewees were asked if either of their parents brewed or fermented their own homemade beer or wine 
She [mother] used to make beer. Homemade beer in a big yellow mug and bottle. And have nettles or whatever it was drying on the line. Drying on the line, nettles and herbs ready for her beer and sometimes she used to tell me before I was born she used to sell it on a Sunday morning to people who came knocking at the door. They loved it. That's when we lived in Manchester before they came up to Salford. ${ }^{27}$

Brewing and selling beer for home consumption may also have been a way to supplement income. Despite regional differences, working-class women from urban and rural areas, made their own beer and wine. In some cases, women made non-alcoholic 'botanic' or herb beer and wine that was drunk by the whole family as a 'tonic' or as a 'treat' but many brewed and fermented alcoholic drinks that were consumed regularly

Interviewer (I): Do you remember your family brewing beer at all?

Interviewee (EP): Herb beer. Everybody brewed herb beer in them days.

That was all made of stinging nettles and various seed cones and you

had to tie the cork down with wire else it'd blow off. That was always

for Sunday dinner.

I: What was it like?

$E P$ : Very good. Wish I had some of it now. ${ }^{28}$

By producing alcoholic drinks that could be consumed at home, working-class women could overcome some of the barriers to drinking posed by gender values. It was perhaps also cheaper to make beer and wine than to buy it from local pubs or licensed grocers. Aside from thrift, there was more privacy in making and consuming alcohol at home and therefore this could have been an attractive option for women who wanted to drink. Yet there was a certain degree of skill involved in making home brew and the cost of equipment and ingredients would have mattered. In A Plain Cookery Book for the Working Classes, published in 1854, there were instructions for making elder wine and homemade beer. ${ }^{29}$ Successful fermenting and brewing were dependent upon a fresh supply of clean water, adequate equipment with the space to house it and of course suitable ingredients. Making homemade beer and wine also took time so given these factors and the constraints of money, space and time faced by many working-class families it is surprising that so many of the interviewees recalled their mothers' making alcoholic drinks. As Mitchell notes, for many working-class families, 'dinner beer' was a staple 
feature of the teatime meal, especially for men coming home from work in the evenings. ${ }^{30}$ It may be that the production of homemade alcohol supplemented the beer bought from pubs and if home brew was sold, it added to the household income.

Many of the working-class families seemed to share the same tastes in the types of alcohol consumed and also made similar choices in terms of drinking venues. Beer, ale and stout were all popular drinks. The interviewees were asked about both their parent's drinking habits and it was clear that men and women's access to alcohol and drinking behaviour varied in terms of gender and region. Some stated that one or both of their parents were teetotallers and never drank any alcohol and a few described problem drinking and alcoholism in the family. Yet the majority recalled their parents' drinking habits as being moderate and governed by concepts of respectability and by financial constraints. In some regions it was socially acceptable for women to drink in pubs, in public and in the company of other women but most interviewees described their mothers drinking at home in the company of husbands or other male relatives. The pub was described largely as a masculine space and this was perhaps most evident in the Worktown study where concepts of masculinity governed drinking preferences and behaviour. The majority of interviewees recalled drinking behaviour that revolved around 'normal' and 'everyday' family life. Some spoke of enduring periods of poverty and hardship during their childhoods, yet few attributed their family's economic circumstances to their parents drinking habits. The interviews painted pictures of hard-working fathers and thrifty, capable mothers for whom drinking alcohol was a small but significant part of their daily lives. In these terms, drinking seemed like a banal activity that was guided by the daily routine of family life and governed by financial constraints. There was nothing carnivalesque about this type of drinking; it was not excessive, nor was it pathological. It was simply another humdrum aspect of working-class family life.

\section{Notes}

1. Thompson P. and Lummis T. 1970/2009. Family Life and Work Experience Before 1918 (1870-1973): 7th Edition, Colchester: Essex: UK Data Archive, accessed May 2009: SN: 2000: https://doi.org/10.5255/ UKDA-SN-2000-1: pp. 170-171.

2. Ibid. 
3. Gusfield J. 1992. 'Benevolent Repression: Popular Culture, Social Structure and the Control of Drinking', in (eds.) Barrows S. and Room R. Drinking Behaviour and Belief in Modern Society: California: University of California Press: pp. 76-91.

4. Thompson P. and Lummis T. 1970/2009.

5. See Appendix B for the full list of data extracted from the study.

6. The Pub and the People: A Worktown Study by Mass Observation. 1943: London: Victor Gollancz.

7. Thompson P. and Lummis T.: Interview No. 39, female born 1891 in London.

8. Thompson P. and Lummis T.: Interview No. 93, male born 1886 in Essex.

9. Rowntree S. 1908/2016. Poverty: A Study of Town Life: London: Macmillan: https://ia800304.us.archive.org/28/items/povertyastudyto00rowngoog/povertyastudyto00rowngoog.pdf: accessed 16/2/16.

10. Rowntree S.: pp. 325-326.

11. Thompson P. and Lummis T.: Interview No. 321, male born in 1899 from Nottingham.

12. The Pub and the People: A Worktown Study by Mass Observation (London: Victor Gollancz, 1943): pp. 10-12.

13. The Pub and the People: pp. 10-12.

14. The Pub and the People: p. 27.

15. Ibid.: p. 43.

16. The Pub and the People: p. 47.

17. Meacham S. 1977. A Life Apart: The English Working Class 1890-1914: London: Thames \& Hudson Ltd.: p. 29.

18. Ibid.: p. 123.

19. Thompson P. and Lummis T.: Interview No. 23, female from Oxford, born 1905.

20. Thompson P. and Lummis T.: Interview 298, Jane Willsher (born 1898), Housewife from London.

21. Thompson P. and Lummis T.: Interview No. 81.

22. Thompson P. and Lummis T.: Interview No. 382.

23. National Brewing Archive (NBA): Bass Advertising Records: c. 1900-1910.

24. NBA: Bass Records: c. 1900-1910.

25. Thompson P. and Lummis T.: Interview No. 96.

26. Thompson P. and Lummis T.: Interview No. 53, female born 1894 in London.

27. Thompson P. and Lummis T.: Interview No. 47, male, born 1902 from Salford. 
28. Thompson P. and Lummis T.: Interview No. 113, male born in London, 1887.

29. Francatelli C. E. 1853/1977. A Plain Cookery Book for the Working Classes: London: Routledge: Beer making: pp. 64-67; Wine making: pp. 57-57.

30. Mitchell S. 1991. Daily Life in Victorian England: Westport: Greenwood Press: p. 127.

Open Access This chapter is licensed under the terms of the Creative Commons Attribution 4.0 International License (http://creativecommons.org/licenses/ by $/ 4.0 /$ ), which permits use, sharing, adaptation, distribution and reproduction in any medium or format, as long as you give appropriate credit to the original author(s) and the source, provide a link to the Creative Commons license and indicate if changes were made.

The images or other third party material in this chapter are included in the chapter's Creative Commons license, unless indicated otherwise in a credit line to the material. If material is not included in the chapter's Creative Commons license and your intended use is not permitted by statutory regulation or exceeds the permitted use, you will need to obtain permission directly from the copyright holder.

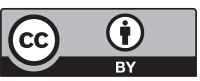

